\title{
In vitro effects of Melaleuca alternifolia essential oil on growth and production of volatile sulphur compounds by oral bacteria
}

\author{
Talita Signoreti GRAZIANO', Caroline Morini CALIL ${ }^{2}$, Adilson SARTORATTO ${ }^{3}$, Gilson César Nobre FRANCO ${ }^{4}$, \\ Francisco Carlos GROPPO5, Karina COGO-MÜLLER ${ }^{6}$
}

\author{
1- Universidade Estadual de Campinas, Faculdade de Odontologia de Piracicaba, Área de Microbiologia e Imunologia, Departamento de Diagnóstico Oral, \\ Piracicaba, SP, Brasil. \\ 2- Centro de Diagnóstico de Halitose - Halicenter, São Paulo, SP, Brasil. \\ 3- Universidade Estadual de Campinas, Centro Pluridisciplinar de Pesquisas Químicas, Biológicas e Agrícolas, Campinas, SP, Brasil. \\ 4- Universidade Estadual de Campinas, Faculdade de Odontologia de Piracicaba, Área de Farmacologia, Anestesiologia e Terapêutica, Departamento de \\ Ciências Fisiológicas, Piracicaba, SP, Brasil. \\ 5- Universidade Estadual de Ponta Grossa, Departamento de Biologia Geral, Laboratório de Fisiologia e Patofisiologia, Ponta Grossa, PR, Brasil. \\ 6- Universidade Estadual de Campinas, Faculdade de Ciências Farmacêuticas, Campinas, SP, Brasil.
}

Corresponding address: Karina Cogo-Müller - Rua Sérgio Buarque de Holanda, 250, CB-II - sala E06 - $2^{\circ}$ Piso - $13083-859$ - Campinas - SP - Brazil - e-mail: karina.muller@fcf.unicamp.br

Submitted: February 19, 2016 - Modification: May 25, 2016 - Accepted: June 21, 2016

\section{ABSTRACT}

$\mathrm{O}$ bjective: Halitosis can be caused by microorganisms that produce volatile sulphur compounds (VSCs), which colonize the surface of the tongue and subgingival sites. Studies have reported that the use of natural products can reduce the bacterial load and, consequently, the development of halitosis. The aim of this study was to evaluate the antimicrobial activity of the essential oil of Melaleuca alternifolia on the growth and volatile sulphur compound (VSC) production of oral bacteria compared with chlorhexidine. Material and Methods: The effects of these substances were evaluated by the Minimum Inhibitory Concentration (MIC) and Minimum Bactericidal Concentration (MBC) in planktonic cultures of Porphyromonas gingivalis and Porphyromonas endodontalis. In addition, gas chromatography analyses were performed to measure the concentration of VSCs from bacterial cultures and to characterize M. alternifolia oil components. Results: The MIC and MBC values were as follows: $M$. alternifolia - P. gingivalis (MIC and $M B C=0.007 \%$ ), $P$. endodontalis (MIC and $M B C=0.007 \%=0.5 \%$ ); chlorhexidine - $P$. gingivalis and $P$. endodontalis ( $M I C$ and $M B C=1.5 \mu \mathrm{g} / \mathrm{mL}$ ). M. alternifolia significantly reduced the growth and production of hydrogen sulfide $\left(\mathrm{H}_{2} \mathrm{~S}\right)$ by $\mathrm{P}$. gingivalis $(p<0.05$, ANOVA-Dunnet) and the $\mathrm{H}_{2} \mathrm{~S}$ and methyl mercaptan $\left(\mathrm{CH}_{3} \mathrm{SH}\right)$ levels of $\mathrm{P}$. endodontalis $(\mathrm{p}<0.05$, ANOVA-Dunnet). Chlorhexidine reduced the growth of both microorganisms without altering the production of VSC in P. endodontalis. For P. gingivalis, the production of $\mathrm{H}_{2} \mathrm{~S}$ and $\mathrm{CH}_{3} \mathrm{SH}$ decreased $(p<0.05$, ANOVA-Dunnet). Conclusion: M. alternifolia can reduce bacterial growth and VSCs production and could be used as an alternative to chlorhexidine.

Keywords: Products with antimicrobial action. Halitosis. Natural products. Porphyromonas gingivalis. Porphyromonas endodontalis.

\section{INTRODUCTION}

Halitosis, also known as bad breath or malodour, is a condition caused by fetid odours present in air emanating from the mouth ${ }^{1}$, leading to personal and social discomfort ${ }^{21}$. The origin of pathological halitosis can be systemic or local ${ }^{14}$ and should be diagnosed and treated ${ }^{1,14,21}$. This condition is multifactorial and may comprise both oral and nonoral causes ${ }^{21,25}$. Periodontal disease, peri-implantitis, deep carious lesions, tongue coating, impacted food or debris, unclean dentures, and other oral problems may contribute to the onset of halitosis ${ }^{9}$.

Oral bad breath can result from the degradation of 
proteins containing sulphur amino acids (methionine and cysteine), resulting in the production of volatile sulphur compounds (VSCs), represented by hydrogen sulfide $\left(\mathrm{H}_{2} \mathrm{~S}\right)$, methyl mercaptan $\left(\mathrm{CH}_{3} \mathrm{SH}\right)$, and dimethyl sulphide $\left[\left(\mathrm{CH}_{3}\right)_{2} \mathrm{~S}\right]$ : gases that emanate malodour ${ }^{1}$. Some anaerobic gramnegative bacteria present in the oral cavity, such as Porphyromonas gingivalis, Fusobacterium nucleatum, Prevotella intermedia, Tannerella forsythia, and Porphyromonas endodontalis, are the main species responsible for the production of $\mathrm{VSCs}^{18}$. In addition to the role of VSCs in generating halitosis, there is evidence suggesting that these gases are also involved in the pathogenesis of periodontal diseases ${ }^{1,29}$.

Various oral approaches have been employed to treat halitosis, including the mechanical removal of tongue and subgingival biofilms, the use of chlorhexidine, cetylpyridinium, or essential oil mouthrinses, and the application of masking products such as chewing gums and mouthrinses containing chlorine dioxide and zinc salts $5,10,23,26$. It has also been reported that natural products, such as green tea, produce effects that control halitosis and VSC production $12,28,30$. Most products used to reduce malodour have antimicrobial properties, and the decrease in VSCs is usually related to the suppression of bacterial growth.

Melaleuca alternifolia, also known as tea tree oil, has been studied because of its antimicrobial activity against oral pathogens, showing inhibitory and bactericidal effects $3,7,8$. A solution containing tea tree oil was shown to reduce the levels of malodour and production of VSCs in patients nursed in an intensive care unit ${ }^{10}$. Despite the antimicrobial potential of $M$. alternifolia, there are few studies evaluating its activity against oral pathogens that cause bad breath ${ }^{4,8}$. Thus, the aim of this study was to evaluate the effects of Melaleuca alternifolia oil and chlorhexidine on the viability and VSC production of $\mathrm{P}$. gingivalis and $\mathrm{P}$. endodontalis.

\section{MATERIAL AND METHODS}

\section{Substances tested}

This study used the essential oil of Melaleuca alternifolia (Arista Industries; Wilton, Connecticut, USA) as the tested substance and chlorhexidine gluconate (Sigma-Aldrich; St. Louis, Missouri, USA) as the standard antimicrobial.

Determination of the chemical profile of M. alternifolia essential oil by gas chromatography-mass spectrometry (GCMS)

The essential oil was subjected to gas chromatography analyses to obtain its chemical profile. Analyses were performed on a gas chromatograph, model: HP-6890 (HP; Palo Alto, California, USA), interfaced with a mass selective detector HP-5975. A fused silica capillary column $\mathrm{HP}-5$ (length of $30 \mathrm{~m}$, internal diameter of 0.25 $\mathrm{mm}$ and film thickness of $0.25 \mathrm{m \mu}$ ) was used with

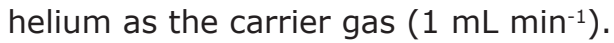

The oil was diluted with ethyl acetate, and 0.1 $\mathrm{mL}$ was injected into the device. The temperatures used were $220^{\circ} \mathrm{C}$ for the injector, $250^{\circ} \mathrm{C}$ for the detector, and $60^{\circ} \mathrm{C}-240^{\circ} \mathrm{C}$ for the column $\left(3^{\circ} \mathrm{C} \mathrm{min}^{-}\right.$ $\left.{ }^{1}\right)$. To identify the analytes, a mixture of n-alkanes was used to calculate the retention index (RI). Comparisons were performed using the National Institute of Standards and Technology (NIST) electronic library and literature data based on RI. The determination of essential oil components was based on the calculation of the area under the peaks.

\section{Bacterial strains and culture conditions}

$P$. gingivalis W83 and P. endodontalis (isolated from clinical sample) were cultivated in Tryptic Soy Broth (TSB - Difco Co.; Detroit, Michigan, USA) or TSA (Tryptic Soy Agar - Difco Co.; Detroit, Michigan, USA), both supplemented with hemin (5 $\mu \mathrm{g} / \mathrm{mL})$, menadione $(1 \mu \mathrm{g} / \mathrm{mL})$, and $2 \%$ of Yeast Extract (Difco Co.; Detroit, Michigan, USA). Growth and cultivation were performed under anaerobic conditions $\left(10 \% \mathrm{CO}_{2}, 10 \% \mathrm{H}_{2}\right.$ and $80 \% \mathrm{~N}_{2}$ ) using an anaerobic chamber (MiniMacs Anaerobic Workstation - Don Whitley Scientific; Shipley, West Yorkshire UK) at $37^{\circ} \mathrm{C}$.

Minimum inhibitory concentration (MIC) and minimum bactericidal concentration (MBC)

MIC and MBC were carried out according to Clinical and Laboratory Standards Institute (CLSI) ${ }^{5}$ with some modifications. For the determination of MIC and MBC, serial two-fold dilutions were made for all substances tested. Concentrations ranged from $0.5 \%(\mathrm{v} / \mathrm{v})$ to $0.002 \%(\mathrm{v} / \mathrm{v})$ for the essential oil of M. alternifolia and from $100 \mu \mathrm{g} / \mathrm{mL}$ $(0.01 \%-p / v)$ to $0.38 \mu \mathrm{g} / \mathrm{mL}(0.0038 \%-p / v)$ for the chlorhexidine solution. An inoculum of $40 \%$ transmittance, equivalent to approximately $8 \times 10^{8}$ $\mathrm{CFU} / \mathrm{mL}$, was prepared from bacterial cultures on TSA with three days of growth, and $500 \mu \mathrm{L}$ samples of this bacterial suspension were transferred to tubes containing the test substances in a final volume of $6 \mathrm{~mL}$. Moreover, tubes without tested compounds or bacterial suspension were used as controls. Cultures were maintained under anaerobic conditions for 48 hours. The lowest concentration of each substance with no bacterial growth was considered the MIC. For MBC determination, 10 $\mu \mathrm{L}$ samples from TSB cultures were transferred to TSA plates and incubated for five days under anaerobic conditions. The lowest concentration with no bacterial growth was considered the MBC. 
In vitro production of Volatile Sulphur Compounds (VSCs)

Sub-MIC concentrations of M. alternifolia oil and chlorhexidine were tested to evaluate their effects on VSC production and to ensure bacterial growth and gas production. Thus, concentrations tested were as follows: $0.002 \%, 0.001 \%$, and $0.0005 \%$ for M. alternifolia; $0.38 \mu \mathrm{g} / \mathrm{mL}(0.0038 \%), 0.19$ $\mu \mathrm{g} / \mathrm{mL}(0.0019 \%), 0.095 \mu \mathrm{g} / \mathrm{mL}(0.00095 \%)$, and $0.048 \mu \mathrm{g} / \mathrm{mL}(0.00048 \%)$ for chlorhexidine digluconate; representing concentrations 4,8 , and 16 times smaller than the MIC ( $4 \mathrm{x}<$ MIC, $8 \mathrm{x}<$ MIC, $16 \mathrm{x}<\mathrm{MIC}$ ).

The inoculum was prepared as described in item 2.3. To collect gas from inside the tubes, needles (Becton Dickinson Company; Franklin Lakes, New Jersey, USA) were coupled with the covers of the tubes. After 16 hours of growth in anaerobic conditions, $1 \mathrm{~mL}$ syringes were attached to the needles, and $0.1 \mathrm{~mL}$ of air was aspirated from inside each tube. The volume of air collected was injected into the OralChroma ${ }^{\mathrm{TM}}$ ( $\mathrm{CHM}-1$, Abilit Corporation;
Chuo-ku, Osaka, Japan). After measurement, the device provided the concentrations of hydrogen sulfite $\left(\mathrm{H}_{2} \mathrm{~S}\right)$, methylmercaptan $\left(\mathrm{CH}_{3} \mathrm{SH}\right)$, and dimethylsulfide $\left[\left(\mathrm{CH}_{3}\right)_{2} \mathrm{~S}\right]$ in parts per billion. The tubes were also subjected to absorbance readings $(\lambda=660 \mathrm{~nm})$ in a Unico 1100 RS spectrophotometer (Unico Inc; Dayton, New Jersey, USA).

\section{Statistical analysis}

All experiments were performed in eight replicates and reproduced at least two times. The Lilliefors test (an adaptation of the KolmogorovSmirnoff test) was used to check the normality of data distribution. For VSC data, analysis of variance (ANOVA) was performed, and the difference among groups was verified by Tukey test, using the BioEstat software (version 5.0 - AnalystSoft Inc./CNPQ; Belém, Pará, Brazil). The significance level was set at $5 \%$.

Table 1- Identification of analytes of $M$. alternifolia essential oil compared with the standard composition recommended by ISO 4730; a) TR - peak retention time (in minutes); b) fraction in percent of total integrated area for the chromatogram

\begin{tabular}{|c|c|c|c|}
\hline$t_{R}(\min )^{(a)}$ & Analytes identified & Relative \% ${ }^{\text {(b) }}$ & $\begin{array}{l}\text { \% recommended } \\
\text { (ISO 4730:2004) }\end{array}$ \\
\hline 4.66 & alpha-thujene & 0.72 & --- \\
\hline 4.84 & alpha-pinene & 1.98 & $1.0-6.0$ \\
\hline 5.87 & beta-pinene & 0.51 & --- \\
\hline 6.23 & beta-myrcene & 0.59 & --- \\
\hline 6.63 & alpha-phellandrene & 0.35 & --- \\
\hline 7.06 & alpha-terpinene & 9.13 & $0.5-13$ \\
\hline 7.27 & p-cymene & 2.49 & $0.5-12$ \\
\hline 7.47 & 1,8-cineole (Eucalyptol) & 3.42 & $\leq 15$ \\
\hline 8.5 & gamma-terpinene & 19.72 & $10-28$ \\
\hline 9.41 & terpinolene & 3.03 & $1.5-5.0$ \\
\hline 13.2 & terpinen-4-ol & 42.07 & $\geq 30$ \\
\hline 13.52 & alpha-terpineol & 2.88 & $1.5-8.0$ \\
\hline 22.19 & alpha-gurjunene & 0.39 & -- \\
\hline 22.58 & trans-caryophyllene & 0.36 & --- \\
\hline 23.39 & aromadendrene & 1.33 & Trace-7.0 \\
\hline 24.24 & alloaromadendrene & 0.58 & --- \\
\hline 25.48 & cis-beta-guaiene & 0.17 & --- \\
\hline 25.85 & alpha-muurolene & 0.14 & --- \\
\hline 26.79 & delta-cadinene & 1.61 & Trace-8.0 \\
\hline 27.09 & cadina-1,4-diene & 0.19 & --- \\
\hline 29.33 & viridiflorol & 0.18 & Trace- 1.5 \\
\hline 29.43 & cubeban-11-ol & 0.16 & --- \\
\hline 30.7 & 1-epi-cubenol & 0.21 & -- \\
\hline 59.58 & squalene & 5.24 & -- \\
\hline
\end{tabular}




\section{RESULTS}

Chemical profile of the essential oil of $M$. alternifolia

The characterization of essential oil compounds was performed by comparing retention times and MS/MS mass spectra of each peak with information in the NIST library. The compounds identified and the percentage range for tea tree oil recommended by ISO 4730:2004 are described in Table 1 .

Minimum Inhibitory Concentration (MIC) and Minimum Bactericidal Concentration (MBC)

The MIC and MBC values for $M$. alternifolia oil and chlorhexidine solution are shown in Table 2 . The tea tree oil and chlorhexidine digluconate solution were able to inhibit the growth of both strains at low concentrations.

\section{In vitro production of Volatile Sulphur Compounds}

The effects of sub-MIC concentrations of tea tree oil and chlorhexidine on the growth and production of volatile sulphur gases $\left(\mathrm{H}_{2} \mathrm{~S}\right.$ and $\left.\mathrm{CH}_{3} \mathrm{SH}\right)$ are shown in figures 1 and 2 for $P$. gingivalis W83, and in Figures 3 and 4 for $P$. endodontalis. Concentrations tested were lower than the minimum inhibitory concentration (sub-MIC concentrations) and were defined in previous tests.

The tea tree oil reduced the growth of $P$. gingivalis W83 and significantly changed the production of $\mathrm{CH}_{3} \mathrm{SH}$ at all concentrations tested $(16 \mathrm{x}<\mathrm{MIC}$, $8 x<$ MIC, and $4 x<$ MIC). Curiously, the $16 x<$ MIC concentration promoted less $\mathrm{CH}_{3} \mathrm{SH}$ production than higher concentrations $(p<0.05)$. The production of $\mathrm{H}_{2} \mathrm{~S}$ was not altered by the essential oil at any of the concentrations. In the presence of chlorhexidine, $P$. gingivalis W83 showed a reduction in growth at concentrations of $8 x<$ MIC and $4 x<M I C$, and they were different from each other $(p<0.05)$. Furthermore, it exhibited a reduction in $\mathrm{CH}_{3} \mathrm{SH}$ levels for all concentrations tested and in $\mathrm{H}_{2} \mathrm{~S}$ for

Table 2- Values of MIC and MBC for M. alternifolia essential oil and for the chlorhexidine digluconate solution

\begin{tabular}{ccccc}
\hline Bacterial Strains & M. alternifolia & Chlorhexidine & M. alternifolia & Chlorhexidine \\
\hline P. gingivalis W83 & $0.007 \%$ & $1.5 \mu \mathrm{g} / \mathrm{ml}(0.00015 \%)$ & $0.007 \%$ & $1.5 \mu \mathrm{g} / \mathrm{ml}(0.00015 \%)$ \\
P. endodontalis & $0.007 \%$ & $1.5 \mu \mathrm{g} / \mathrm{ml}(0.00015 \%)$ & $0.5 \%$ & $1.5 \mu \mathrm{g} / \mathrm{ml}(0.00015 \%)$ \\
\hline
\end{tabular}
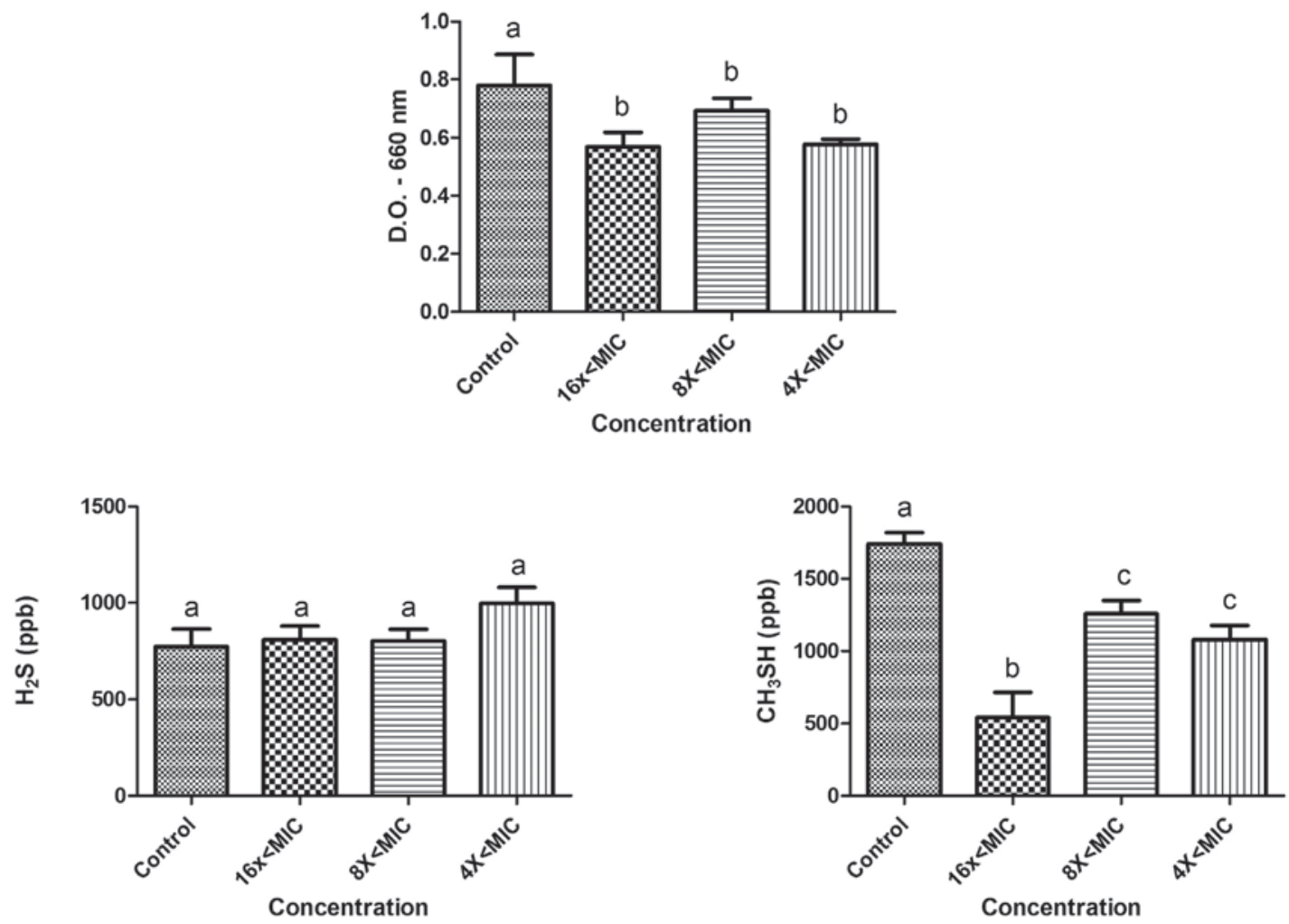

Figure 1- Effects of sub-MIC concentrations of tea tree oil on growth (D.O. - $660 \mathrm{~nm}$ ) and production of volatile sulphur gases $\left(\mathrm{H}_{2} \mathrm{~S}\right.$ and $\left.\mathrm{CH}_{3} \mathrm{SH}\right)$ for $P$. gingivalis W83. Significant differences among treatments and the control group were considered when $p<0.05$ (ANOVA, Tukey test). Different letters represent differences among groups 

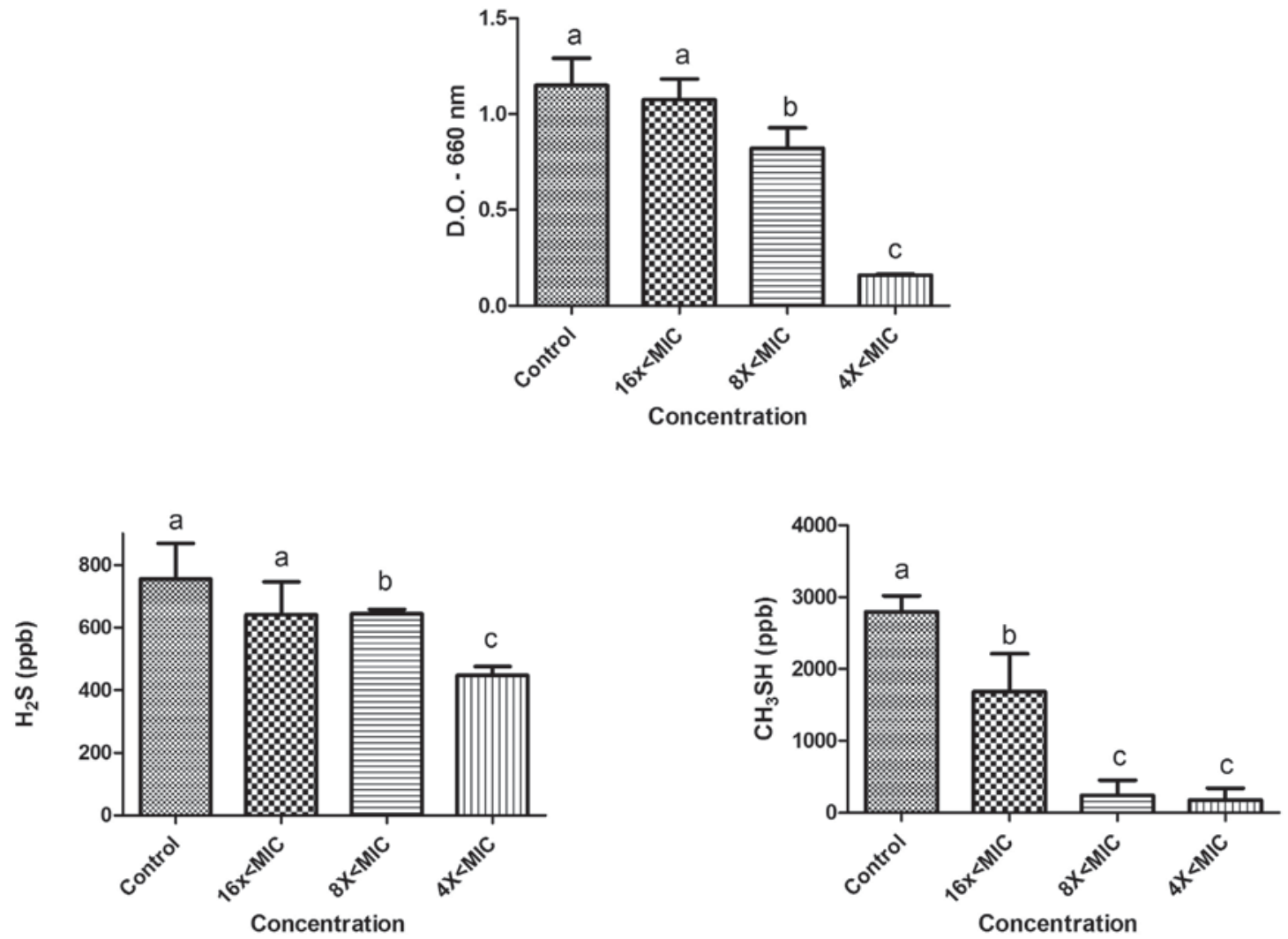

Figure 2- Effects of sub-MIC concentrations of chlorhexidine on growth (D.O. $-660 \mathrm{~nm}$ ) and production of volatile sulphur gases $\left(\mathrm{H}_{2} \mathrm{~S}\right.$ and $\left.\mathrm{CH}_{3} \mathrm{SH}\right)$ for $P$. gingivalis W83. Significant differences among treatments and the control group were considered when $\mathrm{p}<0.05$ (ANOVA, Tukey test). Different letters represent differences among groups
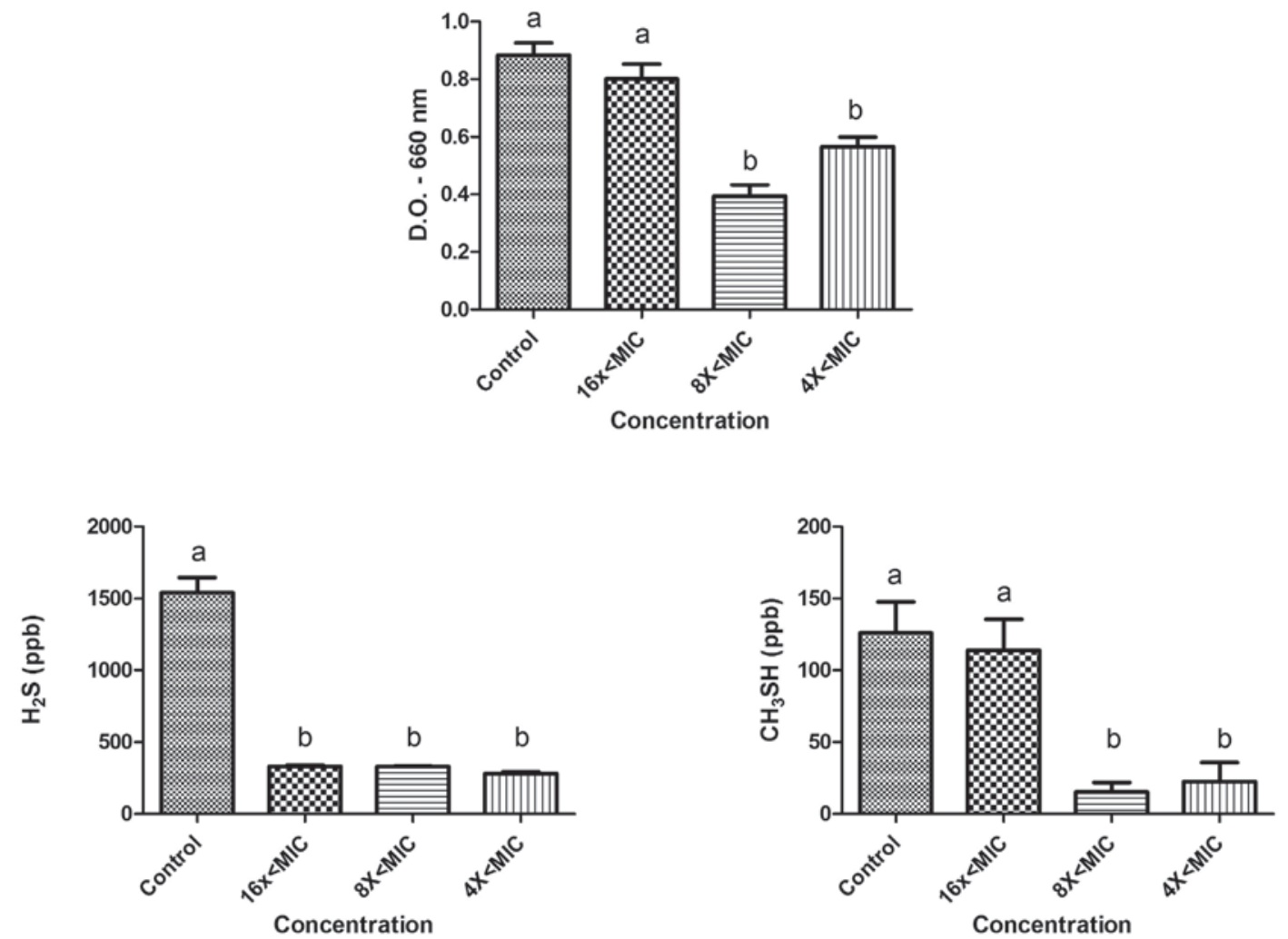

Figure 3- Effects of sub-MIC concentrations of tea tree oil on growth (D.O. - $660 \mathrm{~nm}$ ) and production of volatile sulphur gases $\left(\mathrm{H}_{2} \mathrm{~S}\right.$ and $\left.\mathrm{CH}_{3} \mathrm{SH}\right)$ for $P$. endodontalis. Significant differences among treatments and the control group were considered when $p<0.05$ (ANOVA, Tukey test). Different letters represent differences among groups 

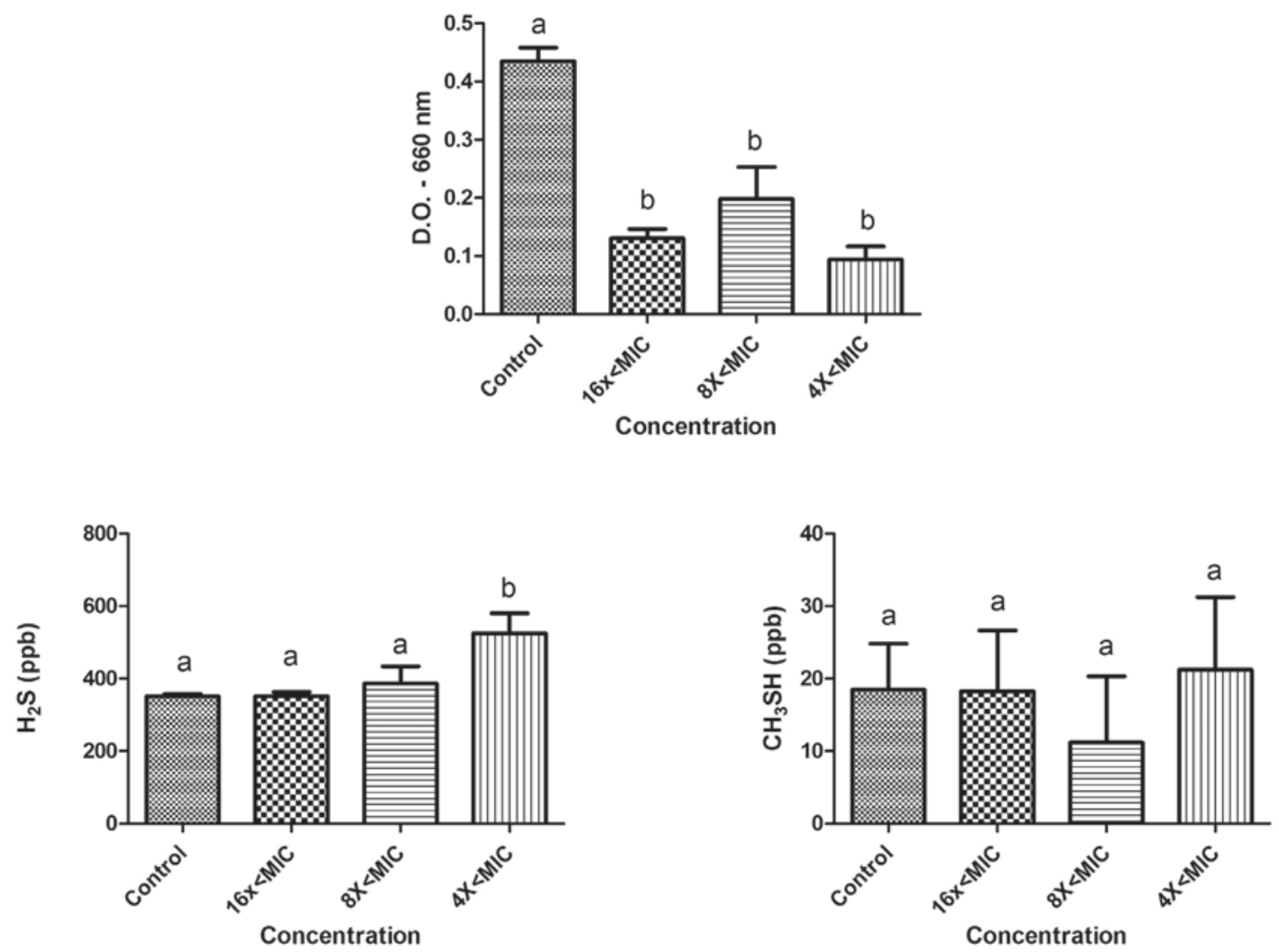

Figure 4- Effects of sub-MIC concentrations of chlorhexidine on growth (D.O. - $660 \mathrm{~nm}$ ) and production of volatile sulphur gases $\left(\mathrm{H}_{2} \mathrm{~S}\right.$ and $\left.\mathrm{CH}_{3} \mathrm{SH}\right)$ for $P$. endodontalis. Significant differences among treatments and the control group were considered when $\mathrm{p}<0.05$ (ANOVA, Tukey test). Different letters represent differences among groups

$8 \mathrm{x}<$ MIC and $4 \mathrm{x}<$ MIC $(\mathrm{p}<0.05)$.

The microorganism $P$. endodontalis showed a reduction in growth in the presence of tea tree oil for concentrations $8 x<$ MIC and $4 x<$ MIC $(p<0.05)$. Decreased gas production was observed for both $\mathrm{H}_{2} \mathrm{~S}(16 \mathrm{x}<\mathrm{MIC}, 8 \mathrm{x}<\mathrm{MIC}$, and $4 \mathrm{x}<\mathrm{MIC})$ and $\mathrm{CH}_{3} \mathrm{SH}$ $(8 x<$ MIC and $4 x<$ MIC $)(p<0.05)$. However, at the concentrations tested, chlorhexidine showed effects on $P$. endodontalis growth $(p<0.05)$ but not on VSC production.

\section{DISCUSSION}

As a result of the significant contribution of VSCs to halitosis development, many studies involving therapies for the treatment of halitosis have focused on the inhibition and reduction of VSC production. Antimicrobial therapy aims to enhance mechanical treatments and support host defences, reducing the development of microorganisms. Some studies have demonstrated the efficacy of $M$. alternifolia against oral bacteria $7,8,11,24$; however, little is known about its effects on VSC production. Here, we showed that M. alternifolia essential oil can reduce growth and VSC levels of P. gingivalis and P. endodontalis, even at sub-MIC concentrations.

GC-MS analysis of the tea tree oil used in this study showed that the composition of this oil was consistent with the International Standard ISO
4730:2004, which specifies certain characteristics of M. alternifolia oil such as quality requirements. The main components described by the ISO for M. alternifolia oil are terpinen-4-ol, $y$-terpinene, a-terpinene, 1,8-cineole, $\mathrm{p}$-cymene, a-terpineol, a-pinene, terpinolene, limonene, and sabinene ${ }^{20}$. All of these compounds were found in the oil used in this study, except for limonene and sabinene. However, these two compounds are generally found in small quantities in tea tree oil $(0.5 \%-4 \%$ and trace $-3.5 \%$, respectively), and their low levels may be the reason they were not identified by CG-MS analysis. In contrast, terpinen-4-ol and a-terpineol, which are substances with antimicrobial activity, were found in satisfactory percentages ${ }^{4,13}$. M. alternifolia have a mixture of components and their mechanisms of action are not completed elucidated. It is known that the combination of these different substances in the tea tree oil are capable of inducing loss of intracellular material, inhibition of respiration, and alterations in the homeostasis, leading to loss of bacterial membrane integrity and function ${ }^{4}$.

The tea tree oil showed antimicrobial activity: its MIC value was $0.007 \%$ for both bacteria, and MBC values were $0.5 \%$ for $P$. endodontalis and $0.007 \%$ for $P$. gingivalis. In a previous study, the MIC value found for $P$. gingivalis was $0.13 \%-0.25 \%$, and the MBC value was $0.13 \%-0.5 \%{ }^{22}$. Although MIC 
values differed between studies, MBC values were similar. Differences in MIC values may be due to different strains tested: in this study we used the W83 strain, while Takarada, et al. ${ }^{22}$ (2004) used the ATCC 33277, 53977, Su63, and W50 strains. To the best of our knowledge, there are no previous studies in the literature showing the effects of $M$. alternifolia on $\mathrm{P}$. endodontalis.

To evaluate the activity of $M$. alternifolia and chlorhexidine on the production of volatile sulphur compounds, sub-inhibitory concentrations of these substances were used. The sub-MIC concentrations of the tea tree oil affected the growth of both microorganisms, reducing the growth at higher concentrations $(8 x<, 4 x<$ MIC, and $16 x<$ MIC). Furthermore, at all concentrations tested, tea tree oil reduced $\mathrm{CH}_{3} \mathrm{SH}$ production in $\mathrm{P}$. gingivalis and both $\mathrm{H}_{2} \mathrm{~S}$ and $\mathrm{CH}_{3} \mathrm{SH}$ production in $\mathrm{P}$. endodontalis. As not expected, the $16 x<$ MIC concentration promoted a higher reduction of $\mathrm{CH}_{3} \mathrm{SH}$ than the $8 \mathrm{x}<$ and $4 \mathrm{x}<\mathrm{MIC}$ concentrations. We believe that higher concentrations of tea tree oil ( $8 x$ and $4 x<$ MIC) could stress the bacteria and stimulate a little the VSC production comparing to the lower concentrations $(16 \mathrm{x}<\mathrm{MIC})$. However, this hypothesis has to be confirmed.

The $\mathrm{CH}_{3} \mathrm{SH}$ and $\mathrm{H}_{2} \mathrm{~S}$ gases are the main VSCs in intra-oral halitosis ${ }^{1}$, and their toxicity is associated with the development of periodontal disease ${ }^{15,16,29}$. Tea tree oil was able to inhibit the growth of $\mathrm{P}$. gingivalis W83 and P. endodontalis, and the production of VSCs. Thus, this essential oil is a promising substance for treating halitosis. Previously, M. alternifolia oil was found to be effective as one of the components of an antiseptic mouth rinse ${ }^{10}$. In addition, a-terpineol, one of the compounds present in tea tree oil and identified in our study, has demonstrated activity against a number of oral pathogens involved in periodontal disease and caries $^{17}$.

Chlorhexidine is widely used in mouthrinses, causing membrane disruption and inhibition of proteolytic and glycosidic enzimes, leading to growth inhibition and cell death ${ }^{27}$. Despite being a potent antimicrobial, it has certain side effects such as altered taste, mucosal desquamation, tooth staining, increased calcified supra-gingival deposits, and a burning sensation in the oral mucosa ${ }^{19}$. Compared with chlorhexidine, tea tree oil showed similar antimicrobial activity, promoting bactericidal and bacteriostatic effects at low concentrations. Thus, tea tree oil could be a good alternative to chlorhexidine in oral hygiene products, mainly mouthrinses. Therefore, the development of new mouthrinses containing tea tree oil and clinical studies testing these products are necessary.

In conclusion, M. alternifolia oil showed antimicrobial activity against $P$. gingivalis W83 and $\mathrm{P}$. endodontalis, reducing the growth and the production of VSCs at sub-MIC concentrations, comparably to chlorhexidine. Future studies can be conducted focusing on the development of pharmaceutical products containing M. alternifolia oil for halitosis treatment.

\section{ACKNOWLEDGEMENTS}

This study was supported by grants from FAPESP - São Paulo Research Foundation (2009/060378 and 2009/14736-3).

\section{REFERENCES}

1- Akaji EA, Folaranmi N, Ashiwaju O. Halitosis: a review of the literature on its prevalence, impact and control. Oral Heal Prev Dent. 2014;124(4):297-304.

2- Aylıkcı BU, Colak H. Halitosis: from diagnosis to management. J Nat Sci Biol Med. 2013;4(1):14-23.

3- Campos Rasteiro VM, Costa AC, Araújo CF, Barros PP, Rossoni $R D$, Anbinder $A L$, et al. Essential oil of Melaleuca alternifolia for the treatment of oral candidiasis induced in an immunosuppressed mouse model. BMC Complement Altern Med. 2014;14:489.

4- Carson CF Riley TV. Antimicrobial activity of the major components of the essential oil of Melaleuca alternifolia. J Appl Bacteriol. 1995;78(3):264-9.

5- Clinical and Laboratory Standards Institute - CLSI. Methods for dilution antimicrobial susceptibility tests for bacteria that grow anaerobically. M11-A7. Wayne: CLSI; 2007.

6- Erovic Ademovski S, Lingström P, Winkel E, Tangerman A, Persson GR Renvert S. Comparison of different treatment modalities for oral halitosis. Acta Odontol Scand. 2012;70(3):22433.

7- Groppo FC, Ramacciato JC, Simões RP, Flório FM Sartoratto A. Antimicrobial activity of garlic, tea tree oil, and chlorhexidine against oral microorganisms. Int Dent J. 2002;52(6):4337.

8- Hammer KA, Dry L, Johnson M, Michalak EM, Carson CF Riley TV. Susceptibility of oral bacteria to Melaleuca alternifolia (tea tree) oil in vitro. Oral Microbiol Immunol. 2003;18(6):389-92.

9- Hinode D, Fukui M, Yokoyama N, Yokoyama M, Yoshioka M, Nakamura R. Relationship between tongue coating and secretory-immunoglobulin A level in saliva obtained from patients complaining of oral malodor. J Clin Periodontol. 2003;30(12):101723.

10- Hur MH, Park J, Maddock-Jennings W, Kim DO, Lee MS. Reduction of mouth malodour and volatile sulphur compounds in intensive care patients using an essential oil mouthwash. Phytother Res. 2007;21(7):641-3.

11- Karbach J, Ebenezer S, Warnke PH, Behrens E, Al-Nawas B. Antimicrobial effect of Australian antibacterial essential oils as alternative to common antiseptic solutions against clinically relevant oral pathogens. Clin Lab. 2015;61(1-2):61-8.

12- Lodhia P, Yaegaki K, Khakbaznejad A, Imai T, Sato T, Tanaka $T$, et al. Effect of green tea on volatile sulfur compounds in mouth air. J Nutr Sci Vitaminol (Tokyo). 2008;54(1):89-94.

13- Loughlin R, Gilmore BF, McCarron PA Tunney MM. Comparison of the cidal activity of tea tree oil and terpinen-4-ol against clinical bacterial skin isolates and human fibroblast cells. Lett Appl Microbiol. 2008;46(4):428-33.

14- Luqman M. Systemic origin of halitosis : a review. Int J Clin Dent Sci. 2012;3(1):15-9.

15- Makino Y, Yamaga T, Yoshihara A, Nohno K, Miyazaki H. Association between volatile sulfur compounds and periodontal disease progression in elderly non-smokers. J Periodontol. 2012;83(5):635-43. 
16- Nakano Y, Yoshimura M, Koga T. Correlation between oral malodor and periodontal bacteria. Microbes Infect. 2002;4(6):67983.

17- Park SN, Lim YK, Freire MO, Cho E, Jin D, Kook JK. Antimicrobial effect of linalool and a-terpineol against periodontopathic and cariogenic bacteria. Anaerobe. 2012;18(3):369-72

18- Persson S, Claesson R Carlsson J. The capacity of subgingival microbiotas to produce volatile sulfur compounds in human serum. Oral Microbiol Immunol. 1989;4(3):169-72.

19- Prayitno S, Addy M. An in vitro study of factors affecting the development of staining associated with the use of chlorhexidine. J Periodontal Res. 1979;14(5):397-402.

20- Sciarrone D, Ragonese C, Carnovale C, Piperno A, Dugo P, Dugo $G$, et al. Evaluation of tea tree oil quality and ascaridole: a deep study by means of chiral and multi heart-cuts multidimensional gas chromatography system coupled to mass spectrometry detection. J Chromatogr A. 2010;1217(41):6422-7.

21- Seemann R, Duarte da Conceição M, Filippi A, Greenman J, Lenton P, Nachnani S, et al. Halitosis management by the general dental practitioner - results of an International Consensus Workshop. Swiss Dent J. 2014;124(11):1205-11.

22- Takarada K, Kimizuka R, Takahashi N, Honma K, Okuda K, Kato T. A comparison of the antibacterial efficacies of essential oils against oral pathogens. Oral Microbiol Immunol. 2004;19(1):61-4. 23- Thaweboon S, Thaweboon B. Effect of an essential oilcontaining mouth rinse on VSC-producing bacteria on the tongue. Southeast Asian J Trop Med Public Heal. 2011;42(2):456-62.
24- Thosar N, Basak S, Bahadure RN, Rajurkar M. Antimicrobial efficacy of five essential oils against oral pathogens: an in vitro study. Eur J Dent. 2013;7(1):1-7.

25- Van den Broek A, Feenstra L, de Baat C. A review of the current literature on management of halitosis. Oral Dis. 2008;14(1):30-9. 26- Van Leeuwen MP, Slot DE, Van der Weijden GA. Essential oils compared to chlorhexidine with respect to plaque and parameters of gingival inflammation: a systematic review. J Periodontol. 2011;82(2):174-94.

27- Van Leeuwen MP, Slot DE, Van der Weijden GA. The effect of an essential-oils mouthrinse as compared to a vehicle solution on plaque and gingival inflammation: a systematic review and meta-analysis. Int J Dent Hyg. 2014;12(3):160-7.

28- Xu X, Zhou XD, Wu CD. Tea catechin EGCg suppresses the mgl gene associated with halitosis. J Dent Res. 2010;89(11):1304-8. 29- Yaegaki K, Qian W, Murata T, Imai T, Sato T, Tanaka T, et al. Oral malodorous compound causes apoptosis and genomic DNA damage in human gingival fibroblasts. J Periodontal Res. 2008;43(4):391-9.

30- Zeng QC, Wu AZ, Pika J. The effect of green tea extract on the removal of sulfur-containing oral malodor volatiles in vitro and its potential application in chewing gum. J Breath Res. 2010;4(3):036005. 